\title{
REVIEW
}

\section{Evolving paradigms in the treatment of relapsed/refractory multiple myeloma: increased options and increased complexity}

RF Cornell and AA Kassim

\begin{abstract}
The use of modern therapies such as thalidomide, bortezomib and lenalidomide coupled with upfront high-dose therapy and autologous stem cell transplant (ASCT) has resulted in improved survival in patients with newly diagnosed multiple myeloma (MM). However, patients with relapsed/refractory multiple myeloma (RRMM) often have poorer clinical outcomes and might benefit from novel therapeutic strategies. Emerging therapies, such as deacetylase inhibitors, monoclonal antibodies and new proteasome inhibitors, appear promising and may change the therapeutic landscape in RRMM. A limited number of studies has shown a benefit with salvage ASCT in patients with RRMM, although there remains ongoing debate about its timing and effectiveness. Improvement in transplant outcomes has re-ignited a debate on the timing and possible role for salvage ASCT and allogeneic stem cell transplant in RRMM. As the treatment options for management of patients with RRMM become increasingly complex, physicians must consider both disease- and patient-related factors in choosing the appropriate therapeutic approach, with the goal of improving efficacy while minimizing toxicity.
\end{abstract}

Bone Marrow Transplantation (2016) 51, 479-491; doi:10.1038/bmt.2015.307; published online 4 January 2016

\section{INTRODUCTION}

Multiple myeloma $(\mathrm{MM})$ is a clonal B-cell disorder of terminally differentiated plasma cells that accounts for $\approx 10 \%$ of hematologic malignancies. ${ }^{1,2}$ It is the second most common hematologic malignancy in the United States, with an overall incidence rate of 4.4 cases per 100000 population/year. ${ }^{3}$ MM remains largely incurable, thus therapy is initiated when patients are symptomatic with the ultimate goal of improving patients' long-term outcomes. ${ }^{4}$ Over the past 10-15 years, the introduction of modern therapies, such as immunomodulatory agents (IMiDs) and proteasome inhibitors (PIs), has led to significant improvements in overall survival (OS). ${ }^{5}$ Five-year survival rates have improved, from $34.8 \%(1998-2001)$ to $44.6 \%(2006-2009)$, in both transplanteligible and transplant-ineligible patients, primarily due to treatment advancements in newly diagnosed MM (NDMM). ${ }^{6-9}$

Patients with relapsed and refractory multiple myeloma (RRMM) present a therapeutic challenge. This heterogeneous group of patients has been defined by the International Myeloma Workshop Consensus Panel as having either primary refractory, refractory, relapsed, both relapsed and refractory, or double refractory MM (Table 1$).{ }^{10}$ In contrast to NDMM, RRMM responds poorly to IMiDs and PIs. Kumar et al. ${ }^{11}$ showed a median survival of only 1.5 years in patients with relapsed MM, and their clinical course was typified by decreasing response duration with increasing number of salvage regimens. Patients with doublerefractory MM, who are refractory to both IMiDs and PIs, have an even poorer prognosis, with a median OS and progression-free survival (PFS) of 9 and 5 months, respectively. ${ }^{5}$

Current treatment strategies are based on both patientand disease-related factors, including pre-existing toxicities, comorbidities, prior response, aggressiveness of relapse and cytogenetics. $^{12-14}$ This review provides an overview of the challenges in the care of patients with RRMM, current treatment options, possible role of hematopoietic stem cell transplant (HSCT), emerging therapies and a proposed strategy for the treatment of patients with RRMM.

\section{THE CHALLENGE IN RRMM-INHERENT DRUG RESISTANCE AND CLONAL EVOLUTION}

The genomic complexity and clonal evolution of MM over the course of treatment are thought to contribute to drug resistance and relapse (Figure 1). ${ }^{15}$ These occur through either the reemergence of the dominant clone, linearly acquired mutations within the dominant clone or evolution of a prediagnostic clone with newly acquired mutations. ${ }^{16}$ Recent advances in genome sequencing have provided evidence of both clonal heterogeneity and shifting clonal dominance over time. ${ }^{16,17}$ Clonal heterogeneity may explain decreased duration of response (DOR) and would warrant sequential therapy with alternate agents. In contrast, patients with a long DOR to their last therapy may have developed a clonal re-emergence and might be responsive to a previous therapy. ${ }^{18,19}$

\section{RISK STRATIFICATION IN RRMM}

The Mayo Stratification for Myeloma and Risk-Adapted Therapy (mSMART) recommendations provide a road map for risk assessment in NDMM and RRMM. ${ }^{20}$ These recommendations suggest that prior cytogenetic abnormalities, as determined by fluorescence in situ hybridization or gene expression profiling, play an important role in risk stratification. ${ }^{20-23}$ Time to relapse should also be considered in determination of risk. Patients who relapse after 24 months of primary therapy are considered standard risk 
Table 1. Definitions of relapsed and refractory disease in multiple myeloma ${ }^{10}$

\begin{tabular}{ll}
\hline Category & Definition \\
\hline Primary refractory multiple myeloma & $\begin{array}{l}\text { Nonresponsive patients who have never achieved minimal response or better with no significant change in } \\
\text { M protein concentration and no evidence of clinical progression }\end{array}$ \\
Refractory multiple myeloma & Nonresponsive while on primary or salvage therapy or progresses within 60 days of last therapy \\
Relapsed multiple myeloma & $\begin{array}{l}\text { Previously treated myeloma that progresses and requires the initiation of salvage therapy but does not meet } \\
\text { criteria for either primary refractory myeloma or relapsed and refractory myeloma categories }\end{array}$ \\
Relapsed and refractory multiple & $\begin{array}{l}\text { Nonresponsive while on salvage therapy or progresses within } 60 \text { days of last therapy in patients who have } \\
\text { myeloma }\end{array}$ \\
achieved minimal response or better at some point previously before, then progress in their disease course \\
(e.g., relapsed and refractory to bortezomib)
\end{tabular}

a

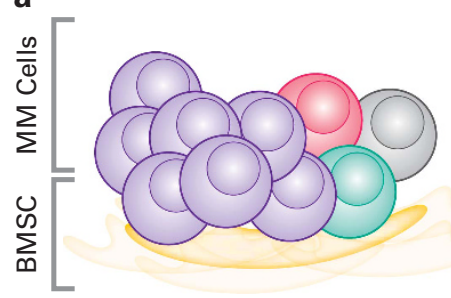

Initial treatment with lenalidomide/dexamethasone; remission for $\approx 2$ years

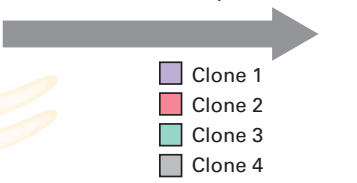

b

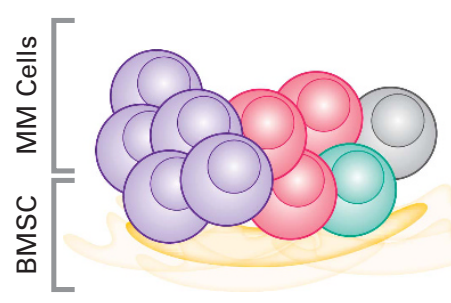

C

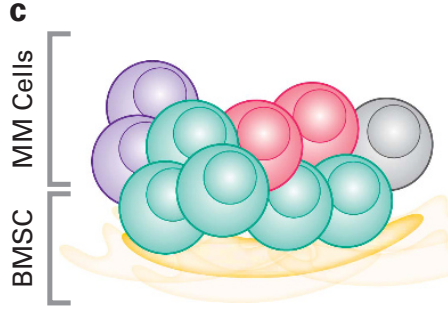

Relapsed MM; clone 1 remains most prominent, retreatment with lenalidomide/dexamethasone, remission within 6 months (1) $\square$ Clone 1 $\square$ Clone 2 $\square$ Clone 3 $\square$ Clone 4

Relapsed and refractory MM; emergence of clone 3, treatment with carfilzomib, remission for 1 year

$\square$ Clone 1
$\square$ Clone 2
$\square$ Clone 3
$\square$ Clone 4

Figure 1. Hypothetical example of clonal evolution and heterogeneity in patients with multiple myeloma (MM) over the disease course. MM is characterized by clonal heterogeneity. As the disease progresses and patients receive various therapies, different clones may emerge and become dominant, thus contributing to treatment resistance typical of patients with relapsed/refractory MM. (a) The clonal distribution at diagnosis, prior to treatment with lenalidomide plus dexamethasone. (b) An emergence of clone 2 at relapse, prior to re-treatment with lenalidomide plus dexamethasone. (c) Emergence of a lenalidomide-resistant clone 3. $\mathrm{BMSC}=$ bone marrow stromal cells.

and are usually re-treated with the primary regimen. Patients who relapse after $<12$ months are classified as high risk, and new agents are incorporated into their therapy. Of note, mSMART does not specifically address the treatment challenges that develop as a result of phenotypic diversity and clonal heterogeneity in RRMM.

\section{CURRENT TREATMENT OPTIONS FOR RRMM}

Patients with RRMM and rapidly increasing monoclonal (M) protein concentration with or without associated symptoms should be considered for salvage therapy. Current treatment standards for RRMM include (1) salvage chemotherapy,
(2) salvage autologous stem cell transplant (ASCT), (3) allogeneic HSCT and (4) post-transplant consolidation/maintenance therapy. Given the concern for acquired drug resistance and clonal evolution of disease, upfront clinical trials incorporating emerging therapies, with/or without addition of stem cell transplant, are being increasingly employed.

\section{SALVAGE CHEMOTHERAPY OPTIONS IN RRMM}

Monotherapy and combination therapies

IMiDs. IMiDs, including thalidomide, pomalidomide and lenalidomide, possess antimyeloma effects via binding to cereblon, a critical component of the E3 ubiquitin ligase complex. This results in enhanced ubiquitination and degradation of Aiolos (IKZF3) and Ikaros (IKZF1), which are important for myeloma cell survival (Figure 2a). ${ }^{24}$

Thalidomide was the first IMiD evaluated in patients with RRMM. A systematic review of phase II studies demonstrated the single-agent efficacy of thalidomide in RRMM, with an overall response rate (ORR; defined as partial response (PR) or better) of $30 \%$ and a median OS of 14 months. ${ }^{25}$ PFS and 3-year survival probabilities were significantly improved when patients with RRMM were treated with thalidomide/dexamethasone compared with conventional chemotherapy (PFS, 17 vs 11 months $(P=0.02)$; 3 -year survival probability, $60 \%$ vs $26 \%(P=0.002)){ }^{26}$ Thalidomideassociated peripheral neuropathy (PN) and venous thromboembolism are the main side effects seen with prolonged use.

Lenalidomide is a more potent thalidomide derivative. Phase I and II trials demonstrated single-agent efficacy of lenalidomide in patients with RRMM, with PR rates of $24-29 \% .{ }^{27}$ MM-009/MM-010 phase III trials demonstrated superior PFS and OS in patients with RRMM receiving lenalidomide/dexamethasone compared with placebo/dexamethasone (Table 2). ${ }^{28,29}$

Pomalidomide is another potent derivative of thalidomide. A phase I study of single-agent pomalidomide in patients with RRMM was efficacious (ORR, 21\%; PFS, 4.6 months; OS, 18.3 months). ${ }^{30}$ The phase ॥ MM-002 study demonstrated an improvement in PFS with pomalidomide/low-dose dexamethasone compared with pomalidomide alone in patients with double-refractory MM (Table 2). ${ }^{31}$ The pivotal phase III MM-003 trial demonstrated a significantly longer PFS and OS with pomalidomide/low-dose dexamethasone compared with high-dose dexamethasone (Table 2). ${ }^{32}$ An ongoing phase III trial (OPTIMISMM, MM-007) is evaluating the safety and efficacy of pomalidomide in combination with bortezomib and dexamethasone (Table 3). ${ }^{33}$

PIs. PIs (i.e., bortezomib and carfilzomib) alter the ability of the proteasome to degrade intracellular proteins that have been targeted for destruction, leading to altered protein homeostasis and plasma cell apoptosis (Figure 2a). ${ }^{34-36}$ Bortezomib was the first PI developed for the treatment of MM. Two phase III trials have demonstrated the efficacy of bortezomib in patients with RRMM (Table 2). ${ }^{37,38}$ In the APEX trial, patients treated with i.v. 
a
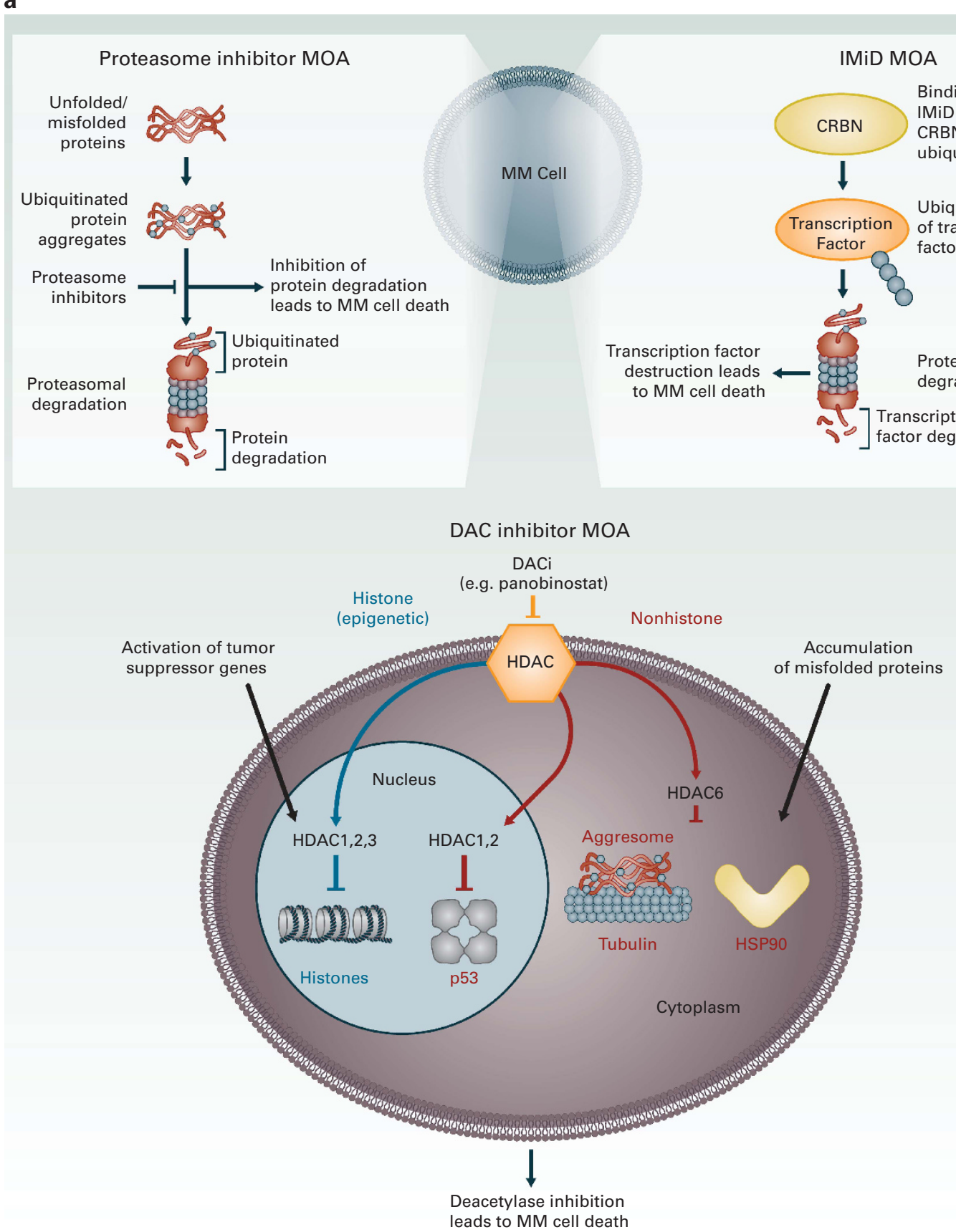

Figure 2. MOA of agents approved or under development for MM. Agents approved or under development for MM target key biological pathways that drive MM cell proliferation and survival. (a) Approved agents include proteasome inhibitors (proteasome inhibitors target the proteasome, which plays a role in the normal degradation and clearance of intracellular misfolded and unfolded proteins. This inhibition leads to protein accumulation and eventual apoptosis), IMiDs (the CRBN E3 ubiquitin ligase complex marks protein with ubiquitin for degradation. The binding of an IMiD to this complex leads to the degradation of two key proteins, Aiolos (IKZF3) and Ikaros (IKZF1), ultimately killing MM cells) and DAC inhibitors (DAC inhibitors target proteins in the nucleus and cytoplasm. HDACs deacetylate target nuclear proteins implicated in gene regulation, including histones and tumor suppressor genes. DACs, which target cytoplasmic proteins, namely HDAC6, play a role in protein metabolism through the formation of aggresomes that transport proteins to be degraded by lysosomes. DAC inhibitors target HDAC6, blocking aggresome formation and subsequent protein degradation, thus leading to protein accumulation and apoptosis). (b) Agents under development: CAR-T cells (CAR-T cells are engineered to recognize target tumor cells and induce cell death), mAbs (mAbs utilize antibodydependent cellular toxicity (targeting of cell surface proteins such as CS1 and CD38) to induce apoptosis; antibody drug conjugates (e.g., indatuximab ravtansine) target cells expressing the recognized receptor, leading to receptor internalization and release of cytotoxic chemotherapy and cell death), oncolytic virotherapy (viruses stimulate MM apoptosis through many complex mechanisms, including direct virus-mediated cytotoxicity and indirect enhancement of immune responses) and KSP inhibitors (KSPs facilitate early mitosis by separating microtubules. KSP inhibitors block this process, thereby serving as antimitotic agents in rapidly dividing MM cells). Adapted with permission from Novartis Pharmaceuticals Corporation. $A=$ antigen; $A D C C=$ antibody-dependent cell-mediated cytotoxicity; $C A R=$ chimeric antigen receptor; $\mathrm{CRBN}=$ cereblon; $\mathrm{HDAC}=$ histone deacetylase; $\mathrm{HSP90}=$ heat-shock protein $90 ; \mathrm{i}=$ inhibitor; $\mathrm{IMiD}=$ immunomodulatory drug; $\mathrm{KSP}=\mathrm{kinesin}$ spindle protein; $\mathrm{mAb}=$ monoclonal antibody; $\mathrm{MM}=$ multiple myeloma; $\mathrm{MOA}=$ mechanism of action; $\mathrm{NK}=$ natural killer; $\mathrm{TCR}=\mathrm{T}$-cell receptor. 
b
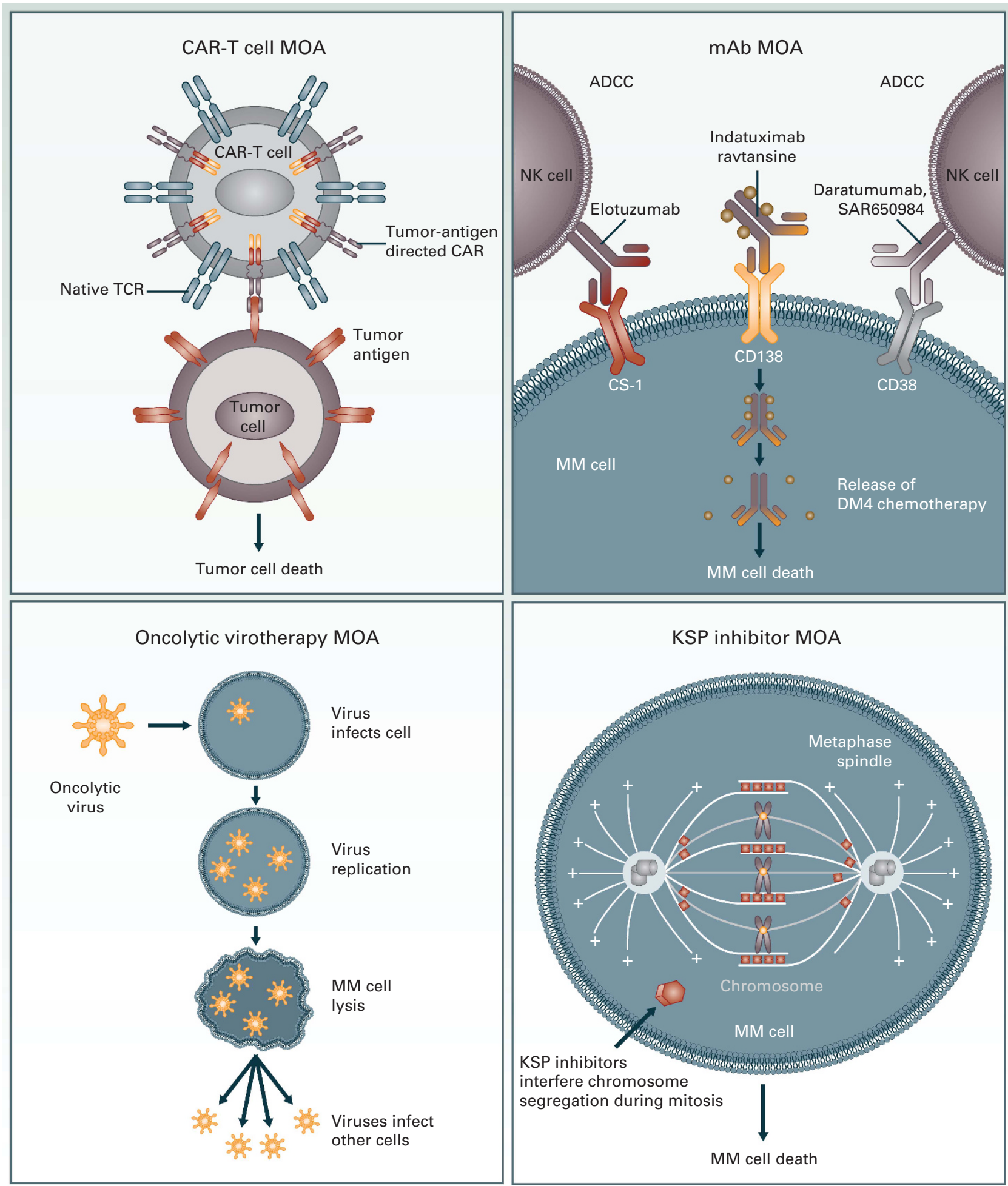

Figure 2. Continued

bortezomib had significantly higher rates of ORR, PFS and 1-year survival compared with high-dose dexamethasone. ${ }^{38}$ However, there was a significantly higher rate of $\mathrm{PN}$ with bortezomib (all grades: $36 \%$ vs $9 \% ; P<0.01$ ). The MMY-3021 trial demonstrated that s.c. bortezomib was comparable in efficacy to i.v. bortezomib and resulted in significantly reduced PN (38\% vs $53 \%$; $P=0.04)^{37}$
Carfilzomib is a second-generation PI that has proven efficacy in RRMM. In the phase II study PX-171-003-A0, carfilzomib achieved an ORR of $16.7 \%$, with a median DOR of 7.2 months. ${ }^{39}$ The phase II study PX-171-004 was designed to assess the effects of carfilzomib in bortezomib-naive patients who had received only 1-3 prior lines of therapy. One cohort was treated with $20 \mathrm{mg} / \mathrm{m}^{2}$ per cycle, while a second cohort was treated with $20 \mathrm{mg} / \mathrm{m}^{2}$ in cycle 1 
Table 2. Selected published clinical trials for the treatment of relapsed/refractory multiple myeloma

\begin{tabular}{|c|c|c|c|c|c|}
\hline Study phase, $\mathrm{N}$ & Treatment & $O R R(\geqslant P R), \%$ & PFS, months & OS, months & Safety, percentage of grade $\geqslant 3$ AEs \\
\hline $\begin{array}{l}\mathrm{MM}-009^{29} \text { Phase III, } \\
\mathrm{N}=353\end{array}$ & Len/D & $\begin{array}{l}60.2 \text { vs } 24 \\
(P<0.001)\end{array}$ & $\begin{array}{l}11.1 \text { vs } 4.7 \\
(P<0.001)\end{array}$ & 29.6 vs $20.2(P<0.001)$ & $\begin{array}{c}\text { Neutropenia ( } 41 \text { vs } 5) \text {, thrombocytopenia } \\
\text { (15 vs } 7) \text {, VTE ( } 15 \text { vs } 4)\end{array}$ \\
\hline $\begin{array}{l}\mathrm{MM}-010^{28} \text { Phase III, } \\
\mathrm{N}=351\end{array}$ & Len/D vs $\mathrm{Pbo} / \mathrm{D}$ & $\begin{array}{l}60.2 \text { vs } 24.0 \\
(P<0.001)\end{array}$ & $\begin{array}{l}11.3 \text { vs } 4.7 \\
(P<0.001)\end{array}$ & NR vs $20.6(P=0.03)$ & $\begin{array}{l}\text { Neutropenia (30 vs } 2) \text {, thrombocytopenia } \\
\text { ( } 11 \text { vs } 6) \text {, VTE ( } 11 \text { vs } 5)\end{array}$ \\
\hline MMY-3021 37 & Subcutaneous BTZ vs & 42 for both & 10.4 vs 9.4 & $72.6 \%$ vs $76.7 \%(P=0.50)$ & Thrombocytopenia (13 vs 19), neutropenia \\
\hline $\begin{array}{l}\mathrm{MM}-002^{31} \text { Phase II, } \\
\mathrm{N}=221\end{array}$ & Pom/D vs Pom & 33 vs 18 & 4.2 vs 2.7 & 16.5 vs 13.6 & $\begin{array}{c}\text { Neutropenia ( } 41 \text { vs } 48) \text {, anemia ( } 22 \text { vs } 24), \\
\text { thrombocytopenia ( } 19 \text { vs } 22)\end{array}$ \\
\hline $\begin{array}{l}\mathrm{MM}-003^{32} \text { Phase III, } \\
\mathrm{N}=302\end{array}$ & Pom/Low D vs High D & 31 vs 10 & $\begin{array}{l}4.0 \text { vs } 1.9 \\
(P<0.0001)\end{array}$ & 12.7 vs $8.1(P=0.03)$ & $\begin{array}{c}\text { Neutropenia ( } 48 \text { vs } 16) \text {, anemia ( } 33 \text { vs } 37), \\
\text { thrombocytopenia ( } 22 \text { vs } 26)\end{array}$ \\
\hline $\begin{array}{l}\text { PANORAMA } 1^{50} \\
\text { Phase } \|=768\end{array}$ & $\begin{array}{l}\text { Panobinostat/BTZ/D } \\
\text { vs Pbo/BTZ/D }\end{array}$ & $\begin{array}{l}61 \text { vs } 55 \\
(P=0.09)\end{array}$ & $\begin{array}{l}12.0 \text { vs } 8.1 \\
(P<00001)\end{array}$ & 33.6 vs $30.4(P=0.26)$ & $\begin{array}{l}\text { Thrombocytopenia ( } 67 \text { vs } 31 \text { ), } \\
\text { Lymphopenia (53 ys } 40 \text { ) diarrhea (26 ys } 8 \text { ) }\end{array}$ \\
\hline
\end{tabular}

Abbreviations: $\mathrm{AE}=$ adverse event; $\mathrm{BTZ}=$ bortezomib; $\mathrm{D}=$ dexamethasone; High=high-dose; Len=lenalidomide; Low $=$ low dose; $\mathrm{NR}=\mathrm{not}$ reached; $\mathrm{ORR}=$ overall response rate; $\mathrm{OS}=$ overall survival; $\mathrm{Pbo}=$ placebo; $\mathrm{PFS}=$ progression-free survival; $\mathrm{Pom}=$ pomalidomide; $\mathrm{PR}=$ partial response; $\mathrm{VTE}=\mathrm{venous}$ thromboembolism.

Table 3. Selected ongoing clinical trials in the treatment of relapsed/refractory multiple myeloma

\begin{tabular}{|c|c|c|c|}
\hline Study & Treatment & Primary end point & Estimated study completion date \\
\hline OPTIMISMM/MM-007 (NCT01734928) ${ }^{33}$ & Pom/BTZ/D vs Pbo/BTZ/D & PFS & January 2017 \\
\hline NCT02136134 ${ }^{114}$ & Daratumumab/BTZ/D vs Pbo/BTZ/D & PFS & March 2017 \\
\hline \multicolumn{4}{|l|}{ Phase III, $N=480$} \\
\hline $\begin{array}{l}\text { ELOQUENT-2 } \\
\text { (NCT01239797) }^{115}\end{array}$ & Elotuzumab/Len/D vs Pbo/Len/D & PFS & March 2018 \\
\hline \multicolumn{4}{|l|}{ Phase III, N = 640} \\
\hline \multicolumn{4}{|l|}{ Phase III, N= 898} \\
\hline NCT01564537 100 & Ixazomib/Len/D vs Pbo/Len/D & PFS & May 2019 \\
\hline \multicolumn{4}{|l|}{ Phase III, $N=703$} \\
\hline NCT02076009 108 & Daratumumab/Len/D vs Pbo/Len/D & PFS & September 2020 \\
\hline Phase III, $N=560$ & & & \\
\hline
\end{tabular}

followed by $27 \mathrm{mg} / \mathrm{m}^{2}$ in subsequent cycles. The ORR was 42.4 and $52.2 \%$ in cohorts 1 and 2, respectively. The median DOR was 13.1 months in cohort 1 and was not reached in cohort $2 .^{40}$ In the phase II study PX-171-003-A1, patients who received a median of 5 prior lines of therapy attained an ORR of $23.7 \%$, with a median DOR of 7.8 months, with carfilzomib. ${ }^{41}$ Higher doses of carfilzomib with prolonged infusions are under investigation. ${ }^{42}$

Deacetylase inhibitors. Histone deacetylases (HDACs) have been identified as a relevant therapeutic target in MM (Figure 2a). ${ }^{34,43}$ HDACs mediate epigenetic silencing of tumor suppressor genes in MM cells, ${ }^{44}$ and overexpression of HDACs has been shown to be a marker of poor prognosis in patients with $\mathrm{MM}^{45}$ In addition to histones, HDACs are known to regulate proteins associated with gene expression, DNA repair and replication, cell cycle, cytoskeleton organization, and chaperone activity. ${ }^{46}$ Of significant interest is HDAC6, which regulates a-tubulin-mediated transport of the aggresome to the lysosome, leading to protein degradation. DAC inhibitors (DACi) block HDAC6 activity and subsequent protein catabolism, leading to altered protein homeostasis and cell death
(Figure 2a). ${ }^{34,47}$ It has been hypothesized that dual targeting of the proteasome and aggresome pathways through PIs and DACi may be effective in patients with RRMM. ${ }^{34}$ Furthermore, DACi have been shown to increase expression of epigenetically silenced tumor suppressor genes in vitro. ${ }^{44}$ Panobinostat, a potent pan-DACi, demonstrated synergistic activity when combined with bortezomib or lenalidomide in preclinical studies. ${ }^{47,48}$ Key phase II (PANORAMA 2) and 3 (PANORAMA 1) clinical trials evaluated panobinostat/ bortezomib/dexamethasone in patients with RRMM (Table 2). ${ }^{49,50}$ PANORAMA 2 showed that the addition of panobinostat to dexamethasone and bortezomib elicited responses in patients who were previously refractory to bortezomib. ${ }^{49}$ In PANORAMA 1, there was a significant improvement in PFS with panobinostat/ bortezomib/dexamethasone compared with placebo/bortezomib/ dexamethasone (Table 2). ${ }^{50}$ PANORAMA 1 was the first phase III trial in a decade to demonstrate a significant and clinically relevant efficacy for an agent with a novel mechanism of action in RRMM. Panobinostat was recently approved by the US Food and Drug Administration for the treatment of relapsed MM patients who had received $\geqslant 2$ prior regimens, including bortezomib and an IMiD. 
Table 4. Selected combination chemotherapy trials for the treatment of relapsed/refractory multiple myeloma

\begin{tabular}{|c|c|c|c|c|c|}
\hline $\begin{array}{l}\text { Study } \\
\text { phase, } \mathrm{N}\end{array}$ & Treatment & $\begin{array}{l}\text { ORR } \\
(\geqslant P R), \%\end{array}$ & PFS, months & OS & Safety (all grades), \% \\
\hline \multicolumn{6}{|c|}{ Pegylated liposomal doxorubicin } \\
\hline $\begin{array}{l}\text { Orlowski et al. }{ }^{117} \\
\text { Phase III, } \mathrm{N}=640\end{array}$ & PLD/BTZ vs BTZ & 44 vs 41 & $\begin{array}{c}9.3 \text { vs } 6.5 \\
(P<0.001)\end{array}$ & $\begin{array}{l}\text { At } 15 \text { months: } \\
76 \% \text { vs } 65 \% \\
(P=0.03)\end{array}$ & $\begin{array}{l}\text { Nausea (46 vs } 37) \text {, diarrhea ( } 43 \text { vs } 34 \text { ), neutropenia } \\
\text { (35 vs } 20)\end{array}$ \\
\hline $\begin{array}{l}\text { Berenson et al. }{ }^{118} \\
\text { Phase II, } \mathrm{N}=40\end{array}$ & PLD/BTZ/Len/Dex & 49 & 9 & NR & Fatigue (40), thrombocytopenia (35), neutropenia (35) \\
\hline \multicolumn{6}{|l|}{ Bendamustine } \\
\hline $\begin{array}{l}\text { Lau et al. }{ }^{119} \\
\text { Phase II, } \mathrm{N}=30\end{array}$ & Ben/Thal/Dex & 46 & 19 & 7.2 months & $\begin{array}{l}\text { Anemia (78), neutropenia (83), thrombocytopenia (65), } \\
\text { pain (48), infection (48), neuropathy (35) }\end{array}$ \\
\hline $\begin{array}{l}\text { Lentzsch et al. }{ }^{120} \\
\text { Phase } 1 / 1 \mathrm{I}, \mathrm{N}=29\end{array}$ & Ben/Len/Dex & 76 & 6.1 & NR & $\begin{array}{c}\text { Thrombocytopenia (83), neutropenia (79), anemia (59), } \\
\text { leukopenia (59), fatigue (45), diarrhea (35), } \\
\text { hypocalcemia (31), hypoglycemia (31), nausea (28) }\end{array}$ \\
\hline $\begin{array}{l}\text { Ludwig } \mathrm{H} \text { et al. }{ }^{121} \\
\text { Phase II, } \mathrm{N}=79\end{array}$ & Ben/BTZ/Dex & 61 & 9.7 & 25.6 months & Infection (66), thrombocytopenia (38), anemia (18) ${ }^{\mathrm{a}}$ \\
\hline \multicolumn{6}{|l|}{ Melphalan } \\
\hline $\begin{array}{l}\text { Palumbo } A \text {, et al. } \\
\mathrm{N}=24\end{array}$ & Mel/Thal/Pre & 42 & 9 & 14 months & $\begin{array}{c}\text { Anemia (100), thrombocytopenia (100), neutropenia (100), } \\
\text { neuralgia, (54), infection (21) }\end{array}$ \\
\hline
\end{tabular}

Combination therapies in RRMM. A number of clinical trials have been designed to test the combinatorial effects of novel agents. In a phase II trial, patients with relapsed MM or RRMM were treated with lenalidomide, bortezomib and dexamethasone (VRd); $6 \%$ of the patients had received prior lenalidomide. The ORR was $64 \%$, with a median PFS of 9.5 months and OS of 30 months. Common toxicities were sensory neuropathy, fatigue and neutropenia. ${ }^{51}$ Another phase II trial compared cyclophosphamide, pomalidomide and dexamethasone (CyPomD) with pomalidomide and dexamethasone in patients with lenalidomide-refractory RRMM. At a median follow-up of 15 months, the ORR was superior in the CyPomD group ( $65 \%$ vs $39 \% ; P=0.03$ ), with improved PFS ( 9.2 vs 4.4 months; $P=0.04) .{ }^{52}$ A multicenter phase I/II trial of carfilzomib, pomalidomide and dexamethasone (CarPomD) was conducted in patients who had received a median of 6 prior lines of therapy. The ORR was $70 \%$, and the median duration of survival and PFS were 17.7 months and 9.7 months, respectively. ${ }^{53}$ In the phase III trial ASPIRE, patients with relapsed MM were randomized to carfilzomib, lenalidomide and dexamethasone versus lenalidomide and dexamethasone. PFS (26.3 vs 17.6 months; $P<0.001)$ and 24 -month OS rates $(73.3 \%$ vs $65 \% ; P=0.04)$ were significantly improved with carfilzomib. ${ }^{54}$ Other combination therapies that include pegylated liposomal doxorubicin, bendamustine and melphalan with dexamethasone, IMiDs and Pls are listed in Table 4. Collectively, these studies suggest that combination therapies with novel agents may improve the disease course in RRMM.

\section{SALVAGE ASCT IN RRMM}

Initial studies revealed that ASCT following high-dose therapy resulted in prolonged control of disease and improved OS; ${ }^{55,56}$ however, additional studies are needed to determine the optimal timing of salvage ASCT in RRMM. ${ }^{57}$ Several retrospective, registrybased or single-center experiences of salvage ASCT after a previous ASCT suggest a benefit with this approach, with an approximate ORRs of $65 \%$ and PFS and OS approaching 12 and 32 months, respectively (Table 5). ${ }^{58-66}$ A phase III study evaluating the efficacy of salvage ASCT compared with conventional chemotherapy demonstrated improvement in PFS, but not OS. Patients with an adverse cytogenetic risk profile had poorer outcomes, suggesting that ASCT may not be beneficial in this subset of patients. ${ }^{67}$ Michaelis et al. showed that 187 patients who underwent a second ASCT for disease relapse/progression, from 1995 to 2008 had a 1-year non-relapse mortality rate of $2 \%$, a complete response (CR) rate of $25 \%$ and a PR rate of $43 \%$, while the risk of relapse or progression was 51,82 and $91 \%$ at 1, 3 and 5 years, respectively. Multivariate analysis showed that a longer interval (>36 months) from the first ASCT to relapse or progression predicted decreased risk of relapse or progression following the second transplant (relative risk, 0.63). ${ }^{63}$ Overall, the use of salvage ASCT in patients with RRMM appears to improve PFS compared with conventional chemotherapy alone. Patients with more aggressive disease, and those with a prolonged response to the first ASCT, appear to benefit the most. Most of the initial studies published using salvage ASCT are limited by being mainly retrospective, having inherent biases in patient selection, and the use of non-modern induction therapies. Future prospective studies are necessary to assess the true impact of salvage ASCT in the context of current, more effective therapies.

\section{ALLOGENEIC STEM CELL TRANSPLANT (ALLO-SCT) IN RRMM}

Allo-SCT is potentially curative in patients with MM; however, its role and timing are still subject to debate. ${ }^{68-70}$ Following allografting, the immune reaction of donor $\mathrm{T}$ cells against myeloma-specific antigens has resulted in the achievement of complete remissions after the discontinuation of immunosuppression or after the infusion of donor $\mathrm{T}$ lymphocytes in patients with recurrent disease post-transplant. ${ }^{71-73} \mathrm{~A}$ complete molecular remission rate up to $50 \%$ has been reported following allo-SCT in MM. ${ }^{74}$

Allo-SCT with myeloablative conditioning has been reported to result in long-term PFS, with a plateau in survival curves suggesting possible curative benefit in some patients. ${ }^{75,76}$ However, transplant-related mortality is an important challenge to this approach. ${ }^{75,77,78}$ A retrospective case-matched analysis by the European Group for Blood and Marrow Transplantation compared 189 myeloma patients treated with allo-SCT with an equal number of patients who received ASCT. Results showed inferior median survival with allo-SCT compared with ASCT, with a median survival of 18 and 34 months, respectively $(P=0.001)$, 
Table 5. Selected studies using salvage ASCT or Allo-SCT in the treatment of relapsed/refractory multiple myeloma

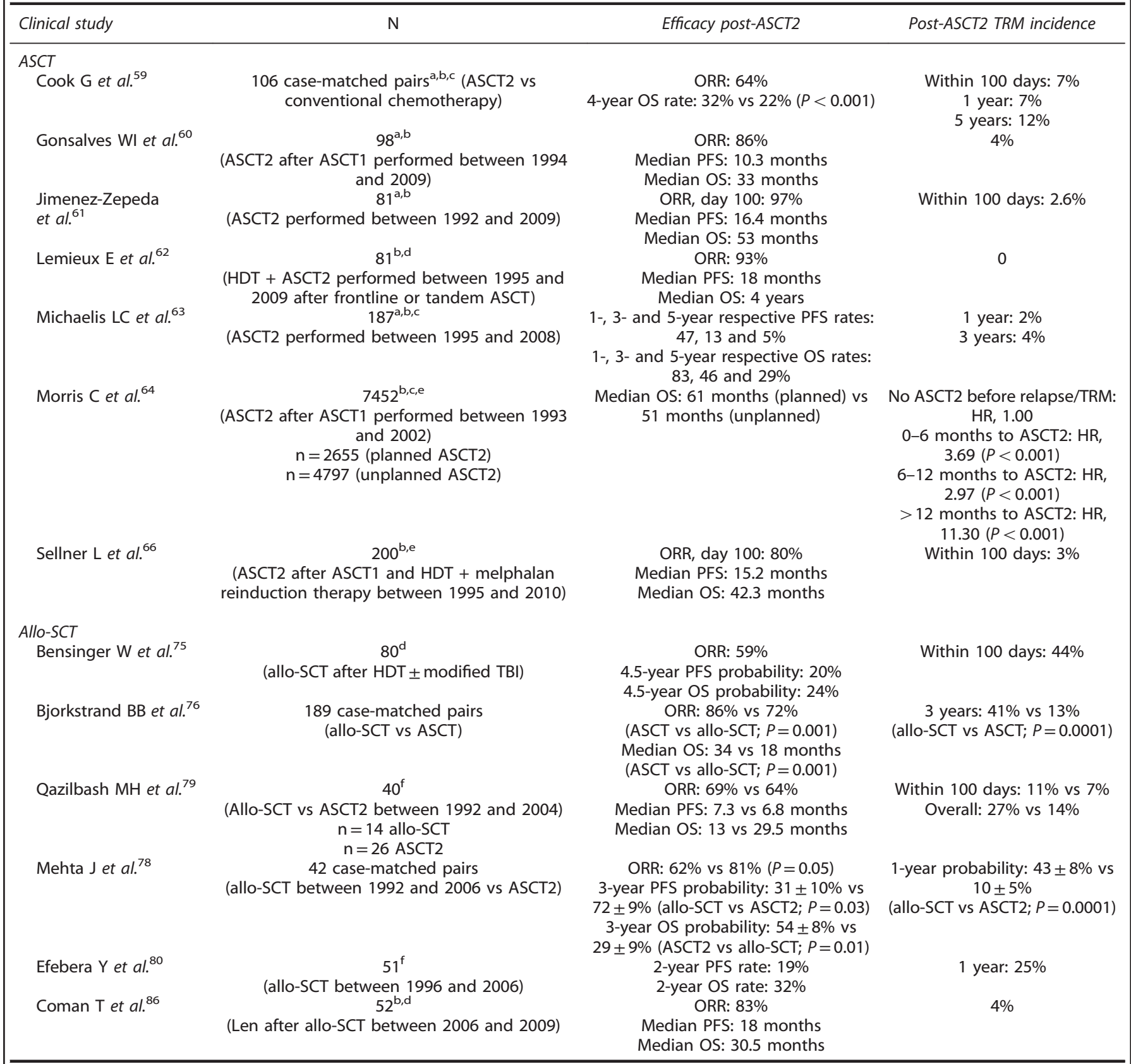

Abbreviations: Allo-SCT=allogeneic stem cell transplant; $\mathrm{ASCT} 1=$ initial autologous $\mathrm{SCT} ; \mathrm{ASCT} 2=$ second autologous $\mathrm{SCT}$; HDT =high-dose chemotherapy; $\mathrm{HR}=$ hazard ratio; $\mathrm{Len}=$ lenalidomide; $\mathrm{ORR}=$ overall response rate; $\mathrm{OS}=$ overall survival; $\mathrm{PFS}=$ progression-free survival; $\mathrm{TBI}=$ total body irradiation; TRM $=$ transplant-related mortality. ${ }^{a}$ Excluded patients participating in a tandem ASCT program. ${ }^{b}$ Retrospective study. ${ }^{c}$ Registry-based study. ${ }^{d}$ Multicenter study. Included patients participating in a tandem ASCT program. ${ }^{f}$ Reduced-intensity myeloablative conditioning was performed prior to allo-SCT.

mainly attributed to increased transplant-related mortality in allo-SCT (41 vs $13 \%$ for ASCT, $P=0.0001$ ), not compensated for by a lower rate of relapse and progression (Table 5). ${ }^{76}$ Transplantrelated mortality may be decreased in patients who receive a reduced-intensity or nonmyeloablative conditioning, allo-SCT following an initial ASCT. ${ }^{79,80}$ In this tandem approach, cytoreduction is achieved with ASCT, and allo-SCT generates a graft-versusmyeloma effect that may be curative. However, results from published studies using this approach appear conflicting in patients with $\mathrm{NDMM}^{81-83}$ attributed to patient heterogeneity, different conditioning regimens and graft-versus-host disease (GVHD) prophylaxis used. Importantly, benefits from an allo-SCT may only become apparent after a long-term follow-up, which most of the published studies lack. However, it remains to be determined whether allo-SCT should be offered as part of the initial therapy in patients with high-risk disease like RRMM or only as a salvage therapy.

\section{POST-TRANSPLANT CONSOLIDATION/MAINTENANCE THERAPY IN RRMM}

Modern therapies with comparatively fewer side effects may be employed as consolidation/maintenance therapy after an autologous and/or allo-SCT. Offidani et al. ${ }^{84}$ showed in a phase II study 
Table 6. Emerging therapies

\begin{tabular}{|c|c|c|c|c|}
\hline Name & Mechanism of action & Route administered & Trial, phase & Combinations \\
\hline \multicolumn{5}{|l|}{ Proteasome inhibitors } \\
\hline Ixazomib & Reversible PI & p.o. or i.v. & $\begin{array}{c}\text { Phase I/II }{ }^{123} \text { NCT01564537, } \\
\text { phase III }\end{array}$ & Lenalidomide, dexamethasone \\
\hline Oprozomib & Irreversible PI & p.o. & NCT01881789, phase lb/ll & $\begin{array}{l}\text { Lenalidomide, dexamethasone, } \\
\text { cyclophosphamide }\end{array}$ \\
\hline Marizomib & Irreversible PI & i.v. & NCT02103335, phase I & Pomalidomide, dexamethasone \\
\hline \multicolumn{5}{|l|}{ Monoclonal antibodies } \\
\hline Elotuzumab & Anti-CS1 & i.v. & NCT01239797, phase III & Lenalidomide, dexamethasone \\
\hline Daratumumab & Anti-CD38 & i.v. & NCT02076009, phase III & Lenalidomide, dexamethasone \\
\hline SAR650984 & Anti-CD38 & i.v. & NCT01749969, phase lb & Lenalidomide, dexamethasone \\
\hline Indatuximab ravtansine & Anti-CD138 & i.v. & NCT01638936 phase I/lla & Lenalidomide, dexamethasone \\
\hline Tabalumab & Anti-BAFF & i.v. & NCT00689507, phase I & Bortezomib \\
\hline Pembrolizumab & Anti-PD-1 & i.v. & NCT02036502, phase I & Lenalidomide, dexamethasone \\
\hline Pidilizumab & Anti-PD-1 & i.v. & NCT02077959, phase I/II & Lenalidomide \\
\hline \multicolumn{5}{|c|}{ Small molecules and signaling pathway inhibitors } \\
\hline Vemurafenib & BRAF $^{\mathrm{V} 600 \mathrm{E}}$ & i.v. & NCT01524978, phase II & None \\
\hline CPI-0610 & BET inhibitor & p.o. & NCT02157636, phase I & None \\
\hline Ibrutinib & Btk inhibitor & p.o. & NCT01962792, phase I/llb & Carfilzomib, dexamethasone \\
\hline Filanesib & KSP inhibitor & i.v. & NCT02092922, phase II & None \\
\hline \multicolumn{5}{|l|}{ Other novel therapies } \\
\hline $\begin{array}{l}\text { Edmonston strain of measles } \\
\text { virus }\end{array}$ & $\begin{array}{l}\text { Oncolytic } \\
\text { virotherapy }\end{array}$ & i.v. & NCT02192775, phase II & None \\
\hline \multirow[t]{2}{*}{ CAR therapy } & Anti-BCMA & i.v. & NCT02215967, phase I & Cyclophosphamide, fludarabine \\
\hline & Anti-CD138 & & NCT01886976, phase I/II & None \\
\hline
\end{tabular}

Abbreviations: $\mathrm{BAFF}=\mathrm{B}$-cell activating factor; $\mathrm{BCMA}=\mathrm{B}$-cell maturation antigen; $\mathrm{Btk}=$ Bruton tyrosine kinase; $\mathrm{BET}=$ bromodomain and extraterminal; $\mathrm{CAR}=$ chimeric antigen receptor; i.v. $=$ intravenous; $\mathrm{KSP}=$ kinesin spindle protein; $\mathrm{PD}-1=$ programmed death $1 ; \mathrm{Pl}=$ proteasome inhibitor; p.o. $=$ per oral .

evaluating the effectiveness of bortezomib-based induction therapy, followed by consolidation/maintenance therapy in patients with RRMM, 37\% CR, 34.5\% very good PR (VGPR) and 4.5\% PR with ORR 76\%. Maintenance lenalidomide after induction therapy with liposomal doxorubicin, vincristine, dexamethasone and lenalidomide led to an ORR of $53 \%$, a median PFS of 10.5 months and a median OS of 19 months. ${ }^{85}$

In addition, these modern therapies modulate T-cell responses, and play a pivotal role in graft-versus-myeloma effects. Following relapse after allo-SCT, use of lenalidomide with or without dexamethasone has shown efficacy, partially through an immunomodulatory GVHD effect to enhance intrinsic anti-MM activity. ${ }^{86}$ Following reduced-intensity or nonmyeloablative conditioning allografting, a cohort of patients with progressive disease treated with lenalidomide developed a flare of GVHD, with improved outcomes. $^{87,88}$

Preclinical studies also have highlighted the immunomodulatory role of bortezomib on GVHD following an allo-SCT. ${ }^{89,90}$ Bortezomib induced selective depletion of alloreactive T lymphocytes, decreased the production of Th1 cytokines and allowed the emergence of a suppressor T-cell subset. ${ }^{91,92}$ Bortezomib in combination with tacrolimus and methotrexate has been found to be effective for GVHD prophylaxis, following reduced-intensity or nonmyeloablative conditioning allografts from human leukocyte antigen-mismatched unrelated donors. ${ }^{93}$ Bortezomib with and without dexamethasone has been shown to be an effective consolidation therapy for prevention of disease relapse, or as a salvage regimen following relapse after an allo-SCT; however, the benefits need to be balanced with potential risks such as increase in infectious complications, worsening of GVHD, and increased neurotoxicity. In a cohort of patients with $\mathrm{MM}^{94,95}$ the use of bortezomib and thalidomide after disease progression following reduced-intensity or nonmyeloablative conditioning allo-SCT and infusion of donor T lymphocytes showed durable responses; ${ }^{96}$ the combination of post-transplant immunotherapy with infusion of donor T lymphocytes and novel agents resulted in increased $C R$ $(>50 \%)$ in patients with only PR after allo-SCT. ${ }^{97}$ Treatment of relapsing patients with modern therapies following allo-SCT may enhance the graft-versus-myeloma effect while directly inhibiting tumor growth. ${ }^{86}$ Future studies are necessary to determine the efficacy and safety of these strategies in RRMM.

\section{EMERGING THERAPIES IN RRMM}

Novel therapies that target different mechanisms of action, including immunotherapy with monoclonal antibodies, are promising, and will expand our therapeutic armamentarium in the fight against MM. Their favorable safety profiles as monotherapy in patients with RRMM will enable combinatorial use with ASCT/allo-SCT to further improve long-term disease control.

\section{New Pls}

Oral PIs (i.e., ixazomib and oprozomib) are currently in clinical development. These agents show promising activity in NDMM as well as in patients with RRMM and are more easily administered (Table 3). Ixazomib has demonstrated enhanced proteasomal inhibition. ${ }^{98}$ In a phase II trial evaluating single-agent ixazomib in patients with relapsed MM, the ORR was $34 \%$. Common toxicities included thrombocytopenia, fatigue and nausea, while the incidence of PN was relatively low (18\%). ${ }^{99}$ An ongoing phase III trial is evaluating the efficacy of ixazomib/lenalidomide/dexamethasone compared with placebo/lenalidomide/dexamethasone in RRMM (Table 3). ${ }^{100}$ Also ixazomib maintenance is being investigated post allo-SCT in high-risk MM (BMT CTN 1302). Oprozomib has also demonstrated antitumor activity in several phase | clinical studies. ${ }^{101,102}$ Gastrointestinal toxicities were common, and PN was rare. 


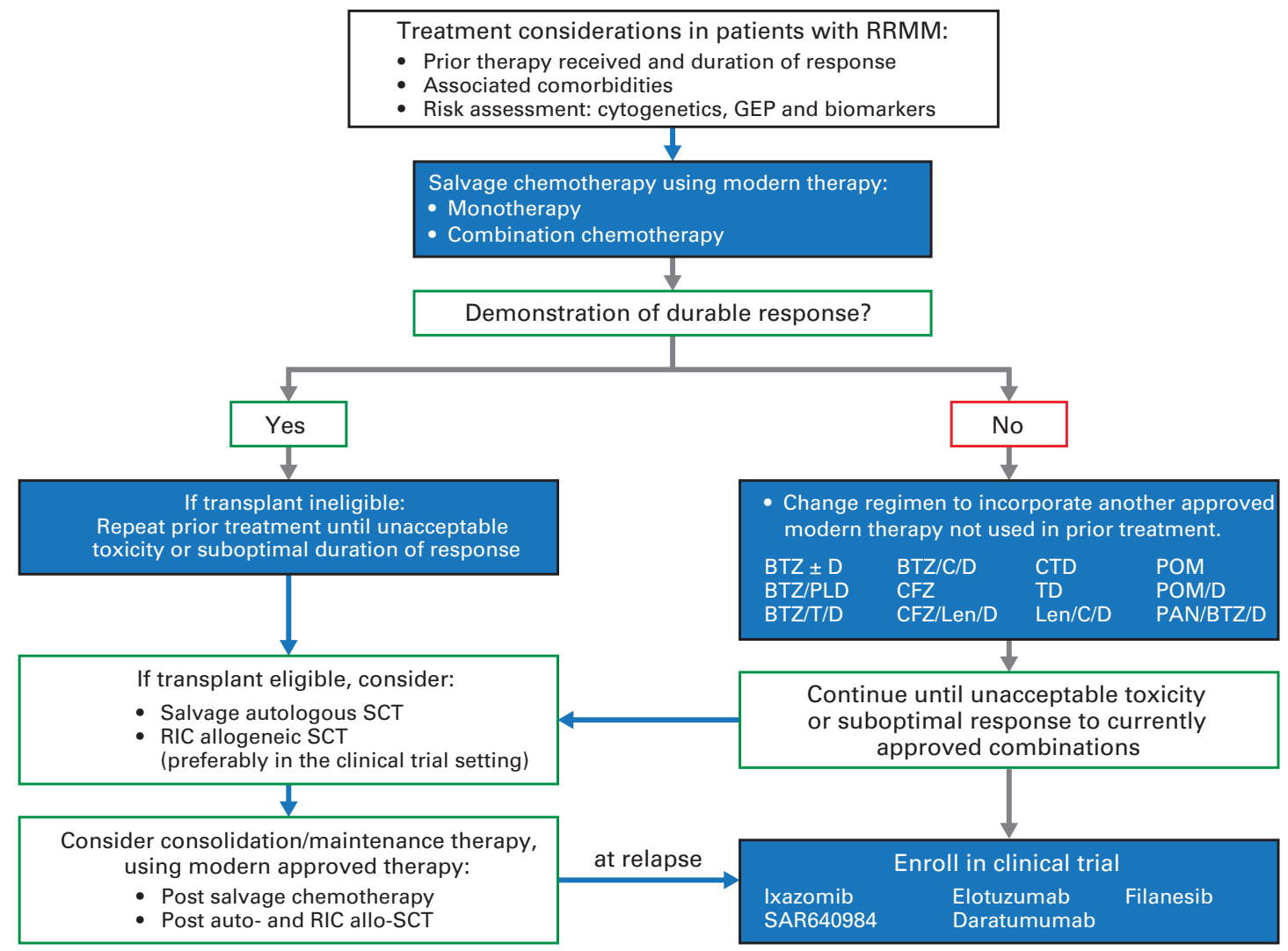

Figure 3. Proposed treatment guidelines for management of relapsed/refractory multiple myeloma (RRMM). Treatment decisions are guided by previous therapeutic exposure, comorbidities, risk assessment and disease- and/or treatment-related symptoms. The availability of new

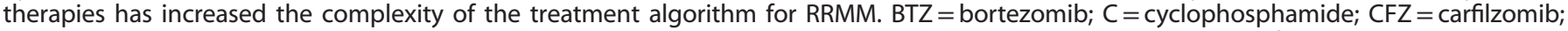
$C T D=$ cyclophosphamide, thalidomide and dexamethasone; $D=$ dexamethasone; $G E P=$ gene expression profiling; Len=lenalidomide; $\mathrm{PLD}=$ pegylated liposomal doxorubicin; $\mathrm{PAN}=$ panobinostat; $\mathrm{POM}=$ pomalidomide; $\mathrm{RIC}=$ reduced-intensity or nonmyeloablative conditioning; $\mathrm{T}=$ thalidomide; $\mathrm{TD}=$ thalidomide and dexamethasone.

\section{Monoclonal antibodies}

Elotuzumab is a humanized monoclonal antibody specifically targeting CS1, a glycoprotein highly expressed on the surface of MM cells. Binding of elotuzumab leads to recruitment of natural killer cells and tumor cell death via antibody-dependent cellular cytotoxicity (Figure 2b). Elotuzumab has recently been granted breakthrough status based on results from a phase II study evaluating elotuzumab/lenalidomide/dexamethasone in patients with RRMM. This combination therapy achieved an ORR of $84 \%$, including $14 \%$ with stringent CR (sCR)/CR and 43\% VGPR). Median PFS was 29 months. Common treatment-related adverse events included gastrointestinal symptoms, muscle spasms, fatigue and upper respiratory tract infection. ${ }^{103}$ Notably, efficacy was greatest among lenalidomide-naive patients. A phase III trial (ELOQUENT-2) evaluating elotuzumab treatment in patients with RRMM showed an ORR in the elotuzumab group of $79 \%$ versus $66 \%$ in the control group $(P<0.001)$, with a relative reduction of $30 \%$ in the risk of disease progression or death after a 2-year follow-up (Table 3). ${ }^{104}$

Daratumumab and SAR650984, humanized monoclonal antibodies specific for CD38, can target tumor cells for elimination via antibody-dependent cellular cytotoxicity, complement-dependent cytotoxicity and phagocytosis. Daratumumab may also initiate CD38-mediated signal transduction, leading to cell death. In preliminary studies, daratumumab has demonstrated promising activity in combination with lenalidomide and dexamethasone. ${ }^{105}$ Most common adverse events were diarrhea and neutropenia, with no dose-limited toxicities. Median time to response was 4.3 weeks, with $75 \%$ PR, 15\% CR and 30\% VGPR. Daratumumab earned breakthrough designation based on phase I results that demonstrated notable single-agent activity with an acceptable safety profile in heavily pretreated patients. ${ }^{106}$ On the basis of these data, two phase III studies are further evaluating daratumumab in RRMM (Table 3). ${ }^{107,108}$ SAR650984 has demonstrated efficacy as a single agent in a phase I study. SAR650984-associated toxicities included fatigue, nausea, pyrexia, cytopenias, cough and gastrointestinal symptoms. The median time to response was 4.6 weeks, with an ORR of $33 \%$ in the highest-dose cohort $(\geqslant 10 \mathrm{mg} / \mathrm{kg}) .{ }^{109}$ In combination with lenalidomide and dexamethasone, the ORR was $64.5 \%$, with $6 \% \mathrm{sCR}$, $26 \%$ VGPR and $32 \%$ PR; the median PFS was 6.2 months. Of note, over $95 \%$ of patients had received prior IMiD therapy. The ORR was $62.5 \%$ among patients who relapsed after or were refractory to prior lenalidomide-containing therapy. ${ }^{109,110}$

Indatuximab ravtansine is a chimeric anti-CD138 monoclonal antibody conjugated to DM4, a maytansinoid cytotoxic agent. After binding to $\mathrm{CD} 138^{+}$myeloma cells, the conjugated antibody is internalized. DM4 is metabolized in the lysosome and released into the cytoplasm, where it inhibits tubulin polymerization, leading to cell death (Figure $2 b$ ). Preliminary results from a phase I/lla trial of indatuximab in combination with lenalidomide and dexamethasone in 30 evaluable patients revealed an ORR of 78\%, with $10 \% \mathrm{sCR} / \mathrm{CR}$ and $33 \%$ VGPR. The most common adverse events were diarrhea, fatigue, nausea and hypokalemia. ${ }^{111}$

Tabalumab, an anti-B-cell activating factor antibody, inhibits interactions between the myeloma cell and its microenvironment that are necessary for survival. ${ }^{112}$ Programmed death 1-specific antibodies, such as pembrolizumab and pidilizmab, enhance the tumor-specific T-cell response. ${ }^{13}$ Two clinical trials are currently evaluating the potential for chimeric antigen receptor (CAR) T cells 
that are engineered to target B-cell maturation antigen or CD138. The small-molecule inhibitors vemurafenib, CPI-0610, ibrutinib, and filanesib (Table 6) and the potent PI marizomib are also in early stages of development. Oncolytic virotherapy (Figure $2 \mathrm{~b}$ and Table 6) is also emerging as a promising therapy for RRMM. New therapeutic agents currently under development for RRMM are included in Table 6.

\section{PROPOSED TREATMENT GUIDELINES FOR RRMM}

Introduction of modern therapies, new and emerging therapies, and improvements in transplant outcomes have increased treatment options for patients with RRMM. The challenge for the physician is to choose the appropriate therapy or combination of therapies to improve outcome. Here we propose a road-map for treatment of patients with RRMM that takes into consideration disease- and patient-related factors, prior treatment response, and history of toxicity (Figure 3). When available, we highly recommend enrollment of patients in clinical trials designed to answer unresolved issues in the treatment of patients with RRMM.

\section{EXPERT COMMENTARY}

Despite substantial progress, myeloma remains an incurable disease plagued by multiple relapses and increasing resistance to therapy. The past decade has been marked by the unraveling of the pathobiological process underlying myeloma pathogenesis, the emergence of new therapies and improvement in transplant technology, which paves the way for improved responses even in patients with double-refractory MM. While randomized trials have shown superiority of modern therapies over older regimens like mephalan-prednisone, very few have shown superiority of one modern therapy over the other in terms of OS and patientreported quality-of-life. Approach to therapy is often dictated by regional availability of drugs, HSCT technology and varied regulatory frameworks that exist in different parts of the world. Thus, there remains marked heterogeneity in how NDMM or RRMM are treated around the world.

Use of new genomic and molecular prognostic tools throughout the disease course may give better insights into the clonal dynamics of the myeloma cell and pave the way for targeted and personalized therapy approaches. Validation of promising biomarkers will help to stratify patients based on risk and potential therapeutic benefit. With the increased complexity of treatment options for patients with RRMM, physicians must understand the guidelines for administration of new agents in the context of the patient's therapeutic and disease history. The strategy provided here may help facilitate a clear path through the complex treatment landscape in RRMM.

\section{CONFLICT OF INTEREST}

RFC declares no potential conflicts of interest. AAK has received research grants from Novartis Pharmaceuticals and Celgene, whose products are discussed in this article.

\section{ACKNOWLEDGEMENTS}

We thank William Fazzone, PhD, for medical editorial assistance with this manuscript, funded by Novartis Pharmaceuticals.

\section{REFERENCES}

1 Katzel JA, Hari P, Vesole DH. Multiple myeloma: charging toward a bright future. CA Cancer J Clin 2007; 57: 301-318.

2 Kyle RA, Rajkumar SV. Multiple myeloma. N Engl J Med 2004; 351: 1860-1873.

3 Ries LAG, Melbert D, Krapcho M, Mariotto A, Miller BA, Feuer EJ et al. SEER Cancer Statistics Review, 1975-2004. National Cancer Institute: Bethesda, MD, 2007. Available at http://seer.cancer.gov/csr/1975_2004/.
4 Chanan-Khan AA, Giralt S. Importance of achieving a complete response in multiple myeloma, and the impact of novel agents. J Clin Oncol 2010; 28: 2612-2624.

5 Kumar SK, Lee JH, Lahuerta JJ, Morgan G, Richardson PG, Crowley J et al. Risk of progression and survival in multiple myeloma relapsing after therapy with IMiDs and bortezomib: a multicenter International Myeloma Working Group study. Leukemia 2012; 26: 149-157.

6 Pulte D, Redaniel MT, Brenner $H$, Jansen L, Jeffreys M. Recent improvement in survival of patients with multiple myeloma: variation by ethnicity. Leuk Lymphoma 2014; 55: 1083-1089.

7 Sonneveld P, Goldschmidt H, Rosinol L, Blade J, Lahuerta JJ, Cavo M et al. Bortezomib-based versus nonbortezomib-based induction treatment before autologous stem-cell transplantation in patients with previously untreated multiple myeloma: a meta-analysis of phase III randomized, controlled trials. J Clin Oncol 2013; 31: 3279-3287.

8 Kumar SK, Lacy MQ, Dispenzieri A, Buadi FK, Hayman SR, Dingli D et al. Early versus delayed autologous transplantation after immunomodulatory agentsbased induction therapy in patients with newly diagnosed multiple myeloma. Cancer 2012; 118: 1585-1592.

9 Gay F, Larocca A, Wijermans P, Cavallo F, Rossi D, Schaafsma R et al. Complete response correlates with long-term progression-free and overall survival in elderly myeloma treated with novel agents: analysis of 1175 patients. Blood 2011; 117: 3025-3031.

10 Rajkumar SV, Harousseau JL, Durie B, Anderson KC, Dimopoulos M, Kyle R et al. Consensus recommendations for the uniform reporting of clinical trials: report of the International Myeloma Workshop Consensus Panel 1. Blood 2011b; 117: 4691-4695.

11 Kumar SK, Therneau TM, Gertz MA, Lacy MQ, Dispenzieri A, Rajkumar SV et al. Clinical course of patients with relapsed multiple myeloma. Mayo Clin Proc 2004; 79: 867-874.

12 Jakubowiak A. Management strategies for relapsed/refractory multiple myeloma: current clinical perspectives. Semin Hematol 2012; 49: S16-S32.

13 Castelli R, Gualtierotti R, Orofino N, Losurdo A, Gandolfi S, Cugno M. Current and emerging treatment options for patients with relapsed myeloma. Clin Med Insights Oncol 2013; 7: 209-219.

14 San Miguel JF. Relapse/refractory myeloma patient: potential treatment guidelines. J Clin Oncol 2009; 27: 5676-5677.

15 Keats JJ, Chesi M, Egan JB, Garbitt VM, Palmer SE, Braggio E et al. Clonal competition with alternating dominance in multiple myeloma. Blood 2012; 120: 1067-1076.

16 Bahlis NJ. Darwinian evolution and tiding clones in multiple myeloma. Blood 2012; 120: 927-928.

17 Walker BA, Wardell CP, Melchor L, Hulkki S, Potter NE, Johnson DC et al. Intraclonal heterogeneity and distinct molecular mechanisms characterize the development of $\mathrm{t}(4 ; 14)$ and $\mathrm{t}(11 ; 14)$ myeloma. Blood 2012; 120: 1077-1086.

18 Madan S, Lacy MQ, Dispenzieri A, Gertz MA, Buadi F, Hayman SR et al. Efficacy of retreatment with immunomodulatory drugs (IMiDs) in patients receiving IMiDs for initial therapy of newly diagnosed multiple myeloma. Blood 2011; 118: 1763-1765.

19 Petrucci MT, Giraldo P, Corradini P, Teixeira A, Dimopoulos MA, Blau IW et al. A prospective, international phase 2 study of bortezomib retreatment in patients with relapsed multiple myeloma. $\mathrm{Br} J$ Haematol 2013; 160: 649-659.

20 Mikhael JR, Dingli D, Roy V, Reeder CB, Buadi FK, Hayman SR et al. Management of newly diagnosed symptomatic multiple myeloma: updated Mayo Stratification of Myeloma and Risk-Adapted Therapy (mSMART) consensus guidelines 2013. Mayo Clin Proc 2013; 88: 360-376.

21 Kumar SK, Mikhael JR, Buadi FK, Dingli D, Dispenzieri A, Fonseca R et al. Management of newly diagnosed symptomatic multiple myeloma: updated Mayo Stratification of Myeloma and Risk-Adapted Therapy (mSMART) consensus guidelines. Mayo Clin Proc 2009; 84: 1095-1110.

22 Stewart AK, Bergsagel PL, Greipp PR, Dispenzieri A, Gertz MA, Hayman SR et al. A practical guide to defining high-risk myeloma for clinical trials, patient counseling and choice of therapy. Leukemia 2007; 21: 529-534.

23 Kuiper R, Broyl A, de Knegt Y, van Vliet MH, van Beers EH, van der Holt B et al. A gene expression signature for high-risk multiple myeloma. Leukemia 2012; 26: 2406-2413.

24 Stewart AK. Medicine. How thalidomide works against cancer. Science 2014; 343: 256-257.

25 Glasmacher A, Hahn C, Hoffmann F, Naumann R, Goldschmidt H, von LilienfeldToal M et al. A systematic review of phase-II trials of thalidomide monotherapy in patients with relapsed or refractory multiple myeloma. Br J Haematol 2006; 132: 584-593. 
26 Palumbo A, Bertola A, Falco P, Rosato R, Cavallo F, Giaccone L et al. Efficacy of low-dose thalidomide and dexamethasone as first salvage regimen in multiple myeloma. Hematol J 2004; 5: 318-324.

27 Richardson P, Jagannath S, Hussein M, Berenson J, Singhal S, Irwin D et al Safety and efficacy of single-agent lenalidomide in patients with relapsed and refractory multiple myeloma. Blood 2009; 114: 772-778.

28 Dimopoulos M, Spencer A, Attal M, Prince HM, Harousseau JL, Dmoszynska A et al. Lenalidomide plus dexamethasone for relapsed or refractory multiple myeloma. N Engl J Med 2007; 357: 2123-2132.

29 Weber DM, Chen C, Niesvizky R, Wang M, Belch A, Stadtmauer EA et al. Lenalidomide plus dexamethasone for relapsed multiple myeloma in North America. N Engl J Med 2007; 357: 2133-2142.

30 Richardson PG, Siegel D, Baz R, Kelley SL, Munshi NC, Laubach J et al. Phase 1 study of pomalidomide MTD, safety, and efficacy in patients with refractory multiple myeloma who have received lenalidomide and bortezomib. Blood 2013; 121: 1961-1967.

31 Richardson PG, Siegel DS, Vij R, Hofmeister CC, Baz R, Jagannath $\mathrm{S}$ et al. Pomalidomide alone or in combination with low-dose dexamethasone in relapsed and refractory multiple myeloma: a randomized phase 2 study. Blood 2014; 123: 1826-1832.

32 San Miguel J, Weisel K, Moreau P, Lacy $M$, Song K, Delforge $M$ et al. Pomalidomide plus low-dose dexamethasone versus high-dose dexamethasone alone for patients with relapsed and refractory multiple myeloma (MM-003): a randomised, open-label, phase 3 trial. Lancet Oncol 2013; 14: 1055-1066.

33 ClinicalTrials.gov. Safety and efficacy of pomalidomide, bortezomib and low-dose dexamethasone in subjects with relapsed or refractory multiple myeloma (OPTIMISMM). Available at http://www.clinicaltrials.gov/ct2/show/ NCT01734928?term = OPTIMISMM\&rank =1. (Accessed 14 May 2015)

34 Hideshima T, Richardson PG, Anderson KC. Mechanism of action of proteasome inhibitors and deacetylase inhibitors and the biological basis of synergy in multiple myeloma. Mol Cancer Ther 2011; 10: 2034-2042.

35 Coux O, Tanaka K, Goldberg AL. Structure and functions of the $20 \mathrm{~S}$ and $26 \mathrm{~S}$ proteasomes. Annu Rev Biochem 1996; 65: 801-847.

36 Hochstrasser M. Ubiquitin, proteasomes, and the regulation of intracellular protein degradation. Curr Opin Cell Biol 1995; 7: 215-223.

37 Moreau P, Pylypenko H, Grosicki S, Karamanesht I, Leleu X, Grishunina M et al. Subcutaneous versus intravenous administration of bortezomib in patients with relapsed multiple myeloma: a randomised, phase 3, non-inferiority study. Lancet Oncol 2011; 12: 431-440.

38 Richardson PG, Sonneveld P, Schuster MW, Irwin D, Stadtmauer EA, Facon T et al. Bortezomib or high-dose dexamethasone for relapsed multiple myeloma. $N$ Engl J Med 2005; 352: 2487-2498.

39 Jagannath $\mathrm{S}$, Vij $\mathrm{R}$, Stewart AK, Trudel $\mathrm{S}$, Jakubowiak AJ, Reiman $\mathrm{T}$ et al. An open-label single-arm pilot phase II study (PX-171-003-A0) of low-dose, single-agent carfilzomib in patients with relapsed and refractory multiple myeloma. Clin Lymphoma Myeloma Leuk 2012; 12: 310-318.

40 Vij R, Wang M, Kaufman JL, Lonial S, Jakubowiak AJ, Stewart AK et al. An open-label, single-arm, phase 2 (PX-171-004) study of single-agent carfilzomib in bortezomib-naive patients with relapsed and/or refractory multiple myeloma. Blood 2012; 119: 5661-5670.

41 Siegel DS, Martin T, Wang M, Vij R, Jakubowiak AJ, Lonial S et al. A phase 2 study of single-agent carfilzomib (PX-171-003-A1) in patients with relapsed and refractory multiple myeloma. Blood 2012; 120: 2817-2825.

42 Papadopoulos KP, Siegel DS, Vesole DH, Lee P, Rosen ST, Zojwalla N et al. Phase study of 30-minute infusion of carfilzomib as single agent or in combination with low-dose dexamethasone in patients with relapsed and/or refractory multiple myeloma. J Clin Oncol 2015; 33: 732-739.

43 Stimson L, Wood V, Khan O, Fotheringham S, La Thangue NB. HDAC inhibitor-based therapies and haematological malignancy. Ann Oncol 2009; 20: 1293-1302.

44 Kalushkova A, Fryknas M, Lemaire M, Fristedt C, Agarwal P, Eriksson M et al. Polycomb target genes are silenced in multiple myeloma. PLOS ONE 2010; 5 e11483.

45 Mithraprabhu S, Kalff A, Chow A, Khong T, Spencer A. Dysregulated Class I histone deacetylases are indicators of poor prognosis in multiple myeloma. Epigenetics 2014; 9: 1511-1520.

46 Choudhary C, Kumar C, Gnad F, Nielsen ML, Rehman M, Walther TC et al. Lysine acetylation targets protein complexes and co-regulates major cellular functions. Science 2009; 325: 834-840.

47 Atadja P. Development of the pan-DAC inhibitor panobinostat (LBH589): successes and challenges. Cancer Lett 2009; 280: 233-241.

48 Ocio EM, Vilanova D, Atadja P, Maiso P, Crusoe E, Fernandez-Lazaro D et al. In vitro and in vivo rationale for the triple combination of panobinostat ( $\mathrm{LBH} 589$ ) and dexamethasone with either bortezomib or lenalidomide in multiple myeloma. Haematologica 2010; 95: 794-803.
49 Richardson PG, Schlossman RL, Alsina M, Weber DM, Coutre SE, Gasparetto C et al. PANORAMA 2: panobinostat in combination with bortezomib and dexamethasone in patients with relapsed and bortezomib-refractory myeloma. Blood 2013; 122: 2331-2337.

50 San-Miguel JF, Hungria VT, Yoon SS, Beksac M, Dimopoulos MA, Elghandour A et al. Panobinostat plus bortezomib and dexamethasone versus placebo plus bortezomib and dexamethasone in patients with relapsed or relapsed and refractory multiple myeloma: a multicentre, randomised, double-blind phase 3 trial. Lancet Oncol 2014; 15: 1195-1206.

51 Richardson PG, Xie W, Jagannath S, Jakubowiak A, Lonial S, Raje NS et al. A phase 2 trial of lenalidomide, bortezomib, and dexamethasone in patients with relapsed and relapsed/refractory myeloma. Blood 2014; 123: 1461-1469.

52 Baz R, Martin TG, Alsina M, Shain KH, Cho HJ, Wolf JL et al. Pomalidomide (Pom) dexamethasone (D) with or without oral weekly cyclophosphamide (Cy) for lenalidomide refractory multiple myeloma (LRMM): a multicenter randomized phase II trial. Blood 2013; 122: 3200 (abstract 3200).

53 Shah JJ, Stadtmauer EA, Abonour R, Cohen A, Bensinger W, Gasparetto C et al. Phase $\mathrm{I} / \mathrm{Il}$ dose expansion of a multi-center trial of carfilzomib and pomalidomide with dexamethasone (Car-Pom-d) in patients with relapsed/refractory multiple myeloma. Blood 2013; 122: 690 (abstract 690).

54 Stewart AK, Rajkumar SV, Dimopoulos MA, Masszi T, Spicka I, Oriol A et al. Carfilzomib, lenalidomide, and dexamethasone for relapsed multiple myeloma. N Engl J Med 2015; 372: 142-152.

55 Attal M, Harousseau JL, Stoppa AM, Sotto JJ, Fuzibet JG, Rossi JF et al. A prospective, randomized trial of autologous bone marrow transplantation and chemotherapy in multiple myeloma. Intergroupe Francais du Myelome. N Engl J Med 1996; 335: 91-97.

56 Child JA, Morgan GJ, Davies FE, Owen RG, Bell SE, Hawkins K et al. High-dose chemotherapy with hematopoietic stem-cell rescue for multiple myeloma. N Engl J Med 2003; 348: 1875-1883.

57 Elice F, Raimondi R, Tosetto A, D'Emilio A, Di Bona E, Piccin A et al. Prolonged overall survival with second on-demand autologous transplant in multiple myeloma. Am J Hematol 2006; 81: 426-431.

58 Atanackovic D, Schilling $\mathrm{G}$. Second autologous transplant as salvage therapy in multiple myeloma. Br J Haematol 2013; 163: 565-572.

59 Cook G, Liakopoulou E, Pearce R, Cavet J, Morgan GJ, Kirkland K et al. Factors influencing the outcome of a second autologous stem cell transplant (ASCT) in relapsed multiple myeloma: a study from the British Society of Blood and Marrow Transplantation Registry. Biol Blood Marrow Transplant 2011; 17: 1638-1645.

60 Gonsalves WI, Gertz MA, Lacy MQ, Dispenzieri A, Hayman SR, Buadi FK et al. Second auto-SCT for treatment of relapsed multiple myeloma. Bone Marrow Transplant 2013; 48: 568-573.

61 Jimenez-Zepeda VH, Mikhael J, Winter A, Franke N, Masih-Khan E, Trudel S et al. Second autologous stem cell transplantation as salvage therapy for multiple myeloma: impact on progression-free and overall survival. Biol Blood Marrow Transplant 2012; 18: 773-779.

62 Lemieux E, Hulin C, Caillot D, Tardy S, Dorvaux V, Michel J et al. Autologous stem cell transplantation: an effective salvage therapy in multiple myeloma. Biol Blood Marrow Transplant 2013; 19: 445-449.

63 Michaelis LC, Saad A, Zhong X, Le-Rademacher J, Freytes CO, Marks DI et al. Salvage second hematopoietic cell transplantation in myeloma. Biol Blood Marrow Transplant 2013; 19: 760-766.

64 Morris C, lacobelli S, Brand R, Bjorkstrand B, Drake M, Niederwieser D et al. Benefit and timing of second transplantations in multiple myeloma: clinical findings and methodological limitations in a European Group for Blood and Marrow Transplantation Registry Study. J Clin Oncol 2004; 22: 1674-1681.

65 Morris C, Cook G, Streetly M, Kettle P, Drake M, Quinn M et al. Re-transplantation after bortezomib-based therapy. Br J Haematol 2011; 153: 666-668.

66 Sellner L, Heiss C, Benner A, Raab MS, Hillengass J, Hose D et al. Autologous retransplantation for patients with recurrent multiple myeloma: a single-center experience with 200 patients. Cancer 2013; 119: 2438-2446.

67 Cook G, Williams C, Brown JM, Cairns DA, Cavenagh J, Snowden JA et al. High-dose chemotherapy plus autologous stem-cell transplantation as consolidation therapy in patients with relapsed multiple myeloma after previous autologous stem-cell transplantation (NCRI Myeloma X Relapse [Intensive trial]): a randomised, open-label, phase 3 trial. Lancet Oncol 2014; 15: 874-885.

68 Bensinger Wl. Role of autologous and allogeneic stem cell transplantation in myeloma. Leukemia 2009; 23: 442-448.

69 Harousseau JL. The allogeneic dilemma. Bone Marrow Transplant 2007; 40: 1123-1128.

70 Gahrton G, Bjorkstrand B. Allogeneic transplantation in multiple myeloma. Haematologica 2008; 93: 1295-1300.

71 Verdonck LF, Lokhorst HM, Dekker AW, Nieuwenhuis HK, Petersen EJ. Graft-versus-myeloma effect in two cases. Lancet 1996; 347: 800-801. 
72 Aschan J, Lonnqvist B, Ringden O, Kumlien G, Gahrton G. Graft-versusmyeloma effect. Lancet 1996; 348: 346.

73 Libura J, Hoffmann T, Passweg J, Gregor M, Favre G, Tichelli A et al. Graft-versus-myeloma after withdrawal of immunosuppression following allogeneic peripheral stem cell transplantation. Bone Marrow Transplant 1999; 24: 925-927.

74 Corradini P, Voena C, Tarella C, Astolfi M, Ladetto M, Palumbo A et al. Molecular and clinical remissions in multiple myeloma: role of autologous and allogeneic transplantation of hematopoietic cells. J Clin Oncol 1999; 17: 208-215.

75 Bensinger WI, Buckner CD, Anasetti C, Clift R, Storb R, Barnett T et al. Allogeneic marrow transplantation for multiple myeloma: an analysis of risk factors on outcome. Blood 1996; 88: 2787-2793.

76 Bjorkstrand BB, Ljungman P, Svensson H, Hermans J, Alegre A, Apperley J et al. Allogeneic bone marrow transplantation versus autologous stem cell transplantation in multiple myeloma: a retrospective case-matched study from the European Group for Blood and Marrow Transplantation. Blood 1996; 88: 4711-4718.

77 Bensinger W. Stem-cell transplantation for multiple myeloma in the era of novel drugs. J Clin Oncol 2008; 26: 480-492.

78 Mehta J, Tricot G, Jagannath S, Ayers D, Singhal S, Siegel D et al. Salvage autologous or allogeneic transplantation for multiple myeloma refractory to or relapsing after a first-line autograft? Bone Marrow Transplant 1998; 21: 887-892.

79 Qazilbash MH, Saliba R, De Lima M, Hosing C, Couriel D, Aleman A et al. Second autologous or allogeneic transplantation after the failure of first autograft in patients with multiple myeloma. Cancer 2006; 106: 1084-1089.

80 Efebera YA, Qureshi SR, Cole SM, Saliba R, Pelosini M, Patel RM et al. Reduced-intensity allogeneic hematopoietic stem cell transplantation for relapsed multiple myeloma. Biol Blood Marrow Transplant 2010; 16: 1122-1129.

81 Bruno B, Giaccone L, Festuccia M, Boccadoro M. Role of allogeneic transplantation in multiple myeloma in the era of new drugs. Mediterr J Hematol Infect Dis 2010; 2: e2010013.

82 Moreau P, Garban F, Attal M, Michallet M, Marit G, Hulin C et al. Long-term follow-up results of IFM99-03 and IFM99-04 trials comparing nonmyeloablative allotransplantation with autologous transplantation in high-risk de novo multiple myeloma. Blood 2008; 112: 3914-3915.

83 Rosinol L, Perez-Simon JA, Sureda A, de la Rubia J, de Arriba F, Lahuerta JJ et al. A prospective PETHEMA study of tandem autologous transplantation versus autograft followed by reduced-intensity conditioning allogeneic transplantation in newly diagnosed multiple myelooma. Blood 2008; 112: 3591-3593.

84 Offidani M, Corvatta L, Polloni C, Gentili S, Mele A, Rizzi R et al. Thalidomide, dexamethasone, Doxil and Velcade (ThaDD-V) followed by consolidation/ maintenance therapy in patients with relapsed-refractory multiple myeloma. Ann Hematol 2011; 90: 1449-1456.

85 Lazaryan A, Hussein MA, Reu FJ, Faiman B, Habecker B, Ann Karam M et al. Mature results of MM-011: a phase I/II trial of liposomal doxorubicin, vincristine, dexamethasone, and lenalidomide combination therapy followed by lenalidomide maintenance for relapsed/refractory multiple myeloma. Am J Hematol 2014; 89: 349-354.

86 Coman T, Bachy E, Michallet $M$, Socie G, Uzunov $M$, Bourhis JH et al. Lenalidomide as salvage treatment for multiple myeloma relapsing after allogeneic hematopoietic stem cell transplantation: a report from the French Society of Bone Marrow and Cellular Therapy. Haematologica 2013; 98: 776-783.

87 Minnema MC, van der Veer MS, Aarts T, Emmelot M, Mutis T, Lokhorst HM. Lenalidomide alone or in combination with dexamethasone is highly effective in patients with relapsed multiple myeloma following allogeneic stem cell transplantation and increases the frequency of CD4+Foxp3+ T cells. Leukemia 2009; 23: 605-607.

88 Lioznov M, El-Cheikh J Jr, Hoffmann F, Hildebrandt Y, Ayuk F, Wolschke C et al. Lenalidomide as salvage therapy after allo-SCT for multiple myeloma is effective and leads to an increase of activated NK (NKp44(+)) and T (HLA-DR(+)) cells. Bone Marrow Transplant 2010; 45: 349-353.

89 Sun K, Welniak LA, Panoskaltsis-Mortari A, O'Shaughnessy MJ, Liu H, Barao l et al. Inhibition of acute graft-versus-host disease with retention of graft-versus-tumor effects by the proteasome inhibitor bortezomib. Proc Natl Acad Sci USA 2004; 101: 8120-8125.

90 Sun K, Wilkins DE, Anver MR, Sayers TJ, Panoskaltsis-Mortari A, Blazar BR et al. Differential effects of proteasome inhibition by bortezomib on murine acute graft-versus-host disease (GVHD): delayed administration of bortezomib results in increased GVHD-dependent gastrointestinal toxicity. Blood 2005; 106: 3293-3299.

91 Blanco B, Perez-Simon JA, Sanchez-Abarca LI, Carvajal-Vergara X, Mateos J, Vidriales $B$ et al. Bortezomib induces selective depletion of alloreactive T lymphocytes and decreases the production of Th1 cytokines. Blood 2006; 107: 3575-3583.
92 Blanco B, Perez-Simon JA, Sanchez-Abarca LI, Caballero-Velazquez T, Gutierrez-Cossio S, Hernandez-Campo $\mathrm{P}$ et al. Treatment with bortezomib of human $\mathrm{CD} 4+\mathrm{T}$ cells preserves natural regulatory $\mathrm{T}$ cells and allows the emergence of a distinct suppressor T-cell population. Haematologica 2009; 94: 975-983.

93 Koreth J, Stevenson KE, Kim HT, Garcia M, Ho VT, Armand P et al. Bortezomib, tacrolimus, and methotrexate for prophylaxis of graft-versus-host disease after reduced-intensity conditioning allogeneic stem cell transplantation from HLA-mismatched unrelated donors. Blood 2009; 114: 3956-3959.

94 Kroger N, Zabelina T, Ayuk F, Atanackovic D, Schieder H, Renges $\mathrm{H}$ et al. Bortezomib after dose-reduced allogeneic stem cell transplantation for multiple myeloma to enhance or maintain remission status. Exp Hematol 2006; 34: 770-775.

95 Bruno B, Patriarca F, Sorasio R, Mattei D, Montefusco V, Peccatori J et al. Bortezomib with or without dexamethasone in relapsed multiple myeloma following allogeneic hematopoietic cell transplantation. Haematologica 2006; 91: 837-839.

96 van de Donk NW, Kroger N, Hegenbart U, Corradini P, San Miguel JF, Goldschmidt $\mathrm{H}$ et al. Remarkable activity of novel agents bortezomib and thalidomide in patients not responding to donor lymphocyte infusions following nonmyeloablative allogeneic stem cell transplantation in multiple myeloma. Blood 2006; 107: 3415-3416.

97 Kroger N, Badbaran A, Lioznov M, Schwarz S, Zeschke S, Hildebrand Y et al. Post-transplant immunotherapy with donor-lymphocyte infusion and novel agents to upgrade partial into complete and molecular remission in allografted patients with multiple myeloma. Exp Hematol 2009; 37: 791-798.

98 Lee EC, Fitzgerald M, Bannerman B, Donelan J, Bano K, Terkelsen J et al. Antitumor activity of the investigational proteasome inhibitor MLN9708 in mouse models of B-cell and plasma cell malignancies. Clin Cancer Res 2011; 17: 7313-7323.

99 Kumar SK, Roy V, Reeder C, Laplant B, Lacy MQ, Gertz M et al. Phase 2 trial of single agent MLN9708 in patients with relapsed multiple myeloma not refractory to bortezomib. Blood 2013; 122 (abstract 1944).

100 ClinicalTrials.gov. A phase 3 study comparing oral IXAZOMIB plus lenalidomide and dexamethasone versus placebo plus lenalidomide and dexamethasone in adult patients with relapsed and/or refractory multiple myeloma. Available at http://www.clinicaltrials.gov/ct2/show/NCT01564537?term = NCT01564537\&rank = 1. (Accessed 14 May 2015).

101 Ghobrial I, Kaufman JL, Siegel D, Vij R, Badros A, Neuman L et al. Clinical profile of single-agent modified-release oprozomib tablets in patients (pts) with hematologic malignancies: updated results from a multicenter, open-label, dose escalation phase 1b/2 study. Blood 2013; 122 (21) (abstract 3184).

102 Kaufman J, Siegel D, Vij R, Ghobrial I, Badros A, Neuman L et al. Clinical profile of once-daily modified-release oprozomib tablets in patients with hematologic malignancies: results of a phase $1 \mathrm{~b} / 2$ trial. European Hematology Association Annual Meeting, Stockholm, Sweden, 2013; (abstract P233).

103 Richardson PG, Jagannath S, Moreau P, Jakubowiak A, Raab MS, Facon T et al. Final results for the 1703 phase $1 \mathrm{~b} / 2$ study of elotuzumab in combination with lenalidomide and dexamethasone in patients with relapsed/refractory multiple myeloma. Blood 2014; 124: 302.

104 Lonial S, Dimopoulos M, Palumbo A, White D, Grosicki S, Spicka I et al. Elotuzumab therapy for relapsed or refractory multiple myeloma. $N$ Engl J Med 2015; 373: 621-631

105 Plesner T, Arkenau HT, Lokhorst HM, Gimsing P, Krejcik J, Lemech C et al. Safety and efficacy of daratumumab with lenalidomide and dexamethasone in relapsed or relapsed, refractory multiple myeloma. Blood 2014; 124: 84 (abstract 84).

106 Lokhorst H, Plesner T, Gimsing P, Nahi H, Lisby S, Richardson P. Daratumumab, a CD38 monoclonal antibody study in advanced multiple myeloma-an openlabel, extension in a single-arm phase i/ll study. European Hematology Assocation Annual Meeting, Milan, Italy, 2014; S576 (abstract S576).

107 ClinicalTrials.gov. An efficacy and safety study of daratumumab in patients with multiple myeloma who have received at least 3 prior lines of therapy (Including a proteasome inhibitor $[\mathrm{PI}]$ and immunomodulatory drug [IMiD]) or are double refractory to a PI and an IMiD. Available at http://www.clinicaltrials. gov/ct2/show/NCT01985126?term $=$ NCT01985126\&rank $=1$. (Accessed 14 May 2015).

108 ClinicalTrials.gov. A study comparing daratumumab, lenalidomide, and dexamethasone with lenalidomide and dexamethasone in relapsed or refractory multiple myeloma. Available at http://www.clinicaltrials.gov/ct2/show/ NCT02076009?term $=$ NCT02076009\&rank $=1$. (Accessed 14 May 2015).

109 Martin TG, Hsu K, Strickland SA, Glenn MJ, Mikhael J, Charpentier E. A phase 1 trial of SAR650984, a CD38 monoclonal antibody, in relapsed or refractory multiple myeloma. J Clin Oncol 2014; 32: 8532 (abstract 8532). 
110 Martin TG, Baz R, Benson DM Jr, Lendvai N, Campana F, Charpentier E et al. A phase $1 \mathrm{~b}$ dose escalation trial of SAR650984 (Anti-CD-38 mAb) in combination with lenalidomide and dexamethasone in relapsed/refractory multiple myeloma. Blood 2014; 124: 83 (abstract 83).

111 Kelly KR, Chanan-Khan A, Heffner LT, Somlo G, Siegel DS, Zimmerman T et al. Indatuximab ravtansine (BT062) in combination with lenalidomide and low-dose dexamethasone in patients with relapsed and/or refractory multiple myeloma: clinical activity in patients already exposed to lenalidomide and bortezomib. Blood 2014; 124: 4736-4736.

112 Hengeveld PJ, Kersten MJ. B-cell activating factor in the pathophysiology of multiple myeloma: a target for therapy? Blood Cancer J 2015; 5: e282.

113 Bryan LJ, Gordon LI. Blocking tumor escape in hematologic malignancies: the anti-PD-1 strategy. Blood Rev 2015; 29: 25-32.

114 ClinicalTrials.gov. Addition of daratumumab to combination of bortezomib and dexamethasone in participants with relapsed or refractory multiple myeloma. Available at http://www.clinicaltrials.gov/ct2/show/NCT02136134?term = dar atumumab\&rank = 7. (Accessed 14 May 2015).

115 ClinicalTrials.gov. Phase III, randomized, open label trial of lenalidomide/ dexamethasone with or without elotuzumab in relapsed or refractory multiple myeloma (ELOQUENT-2). 2012; 2012. Available at http://www.clinicaltrials.gov/ ct2/show/NCT01239797 (Accessed 14 May 2015).

116 ClinicalTrials.gov Phase III study with carfilzomib and dexamethasone versus velcade and dexamethasone for relapsed multiple myeloma patients (ENDEAVOR). Available at http://www.clinicaltrials.gov/ct2/show/NCT01568866. (Accessed 14 May 2015).

117 Orlowski RZ, Nagler A, Sonneveld P, Blade J, Hajek R, Spencer A et al Randomized phase III study of pegylated liposomal doxorubicin plus bortezomib compared with bortezomib alone in relapsed or refractory multiple myeloma: combination therapy improves time to progression. J Clin Oncol 2007; 25: 3892-3901.

118 Berenson JR, Yellin O, Kazamel T, Hilger JD, Chen CS, Cartmell A et al. A phase 2 study of pegylated liposomal doxorubicin, bortezomib, dexamethasone and lenalidomide for patients with relapsed/refractory multiple myeloma. Leukemia 2012; 26: 1675-1680.

119 Lau IJ, Smith D, Aitchison R, Blesing N, Roberts P, Peniket A et al. Bendamustine in combination with thalidomide and dexamethasone is a viable salvage option in myeloma relapsed and/or refractory to bortezomib and lenalidomide. Ann Hematol 2015; 94: 643-649.

120 Lentzsch S, O'Sullivan A, Kennedy RC, Abbas M, Dai L, Pregja SL et al. Combination of bendamustine, lenalidomide, and dexamethasone (BLD) in patients with relapsed or refractory multiple myeloma is feasible and highly effective: results of phase 1/2 open-label, dose escalation study. Blood 2012; 119: 4608-4613.

121 Ludwig H, Kasparu H, Leitgeb C, Rauch E, Linkesch W, Zojer N et al. Bendamustine-bortezomib-dexamethasone is an active and well-tolerated regimen in patients with relapsed or refractory multiple myeloma. Blood 2014; 123: 985-991.

122 Palumbo A, Avonto I, Bruno B, Ambrosini MT, Bringhen S, Cavallo F et al. Intravenous melphalan, thalidomide and prednisone in refractory and relapsed multiple myeloma. Eur J Haematol 2006; 76: 273-277.

123 Kumar SK, Berdeja JG, Niesvizky R, Lonial S, Laubach JP, Hamadani M et al. Safety and tolerability of ixazomib, an oral proteasome inhibitor, in combination with lenalidomide and dexamethasone in patients with previously untreated multiple myeloma: an open-label phase 1/2 study. Lancet Oncol 2014; 15: 1503-1512.

(i) $\Theta$ This work is licensed under a Creative Commons AttributionNon No No Nomercial-NoDerivs 4.0 International License. The images or other third party material in this article are included in the article's Creative Commons license, unless indicated otherwise in the credit line; if the material is not included under the Creative Commons license, users will need to obtain permission from the license holder to reproduce the material. To view a copy of this license, visit http:// creativecommons.org/licenses/by-nc-nd/4.0/ 